\title{
Rosai-Dorfman disease: an overview
}

\author{
Cassandra Bruce-Brand (10) 1,2 Johann W Schneider, ${ }^{1,2}$ Pawel Schubert ${ }^{1,2}$
}

${ }^{1}$ Stellenbosch University, Faculty of Medicine and Health Sciences, Division of Anatomical Pathology, Cape Town, South Africa

${ }^{2}$ National Health Laboratory Service, Tygerberg Hospital, Cape Town, South Africa

\section{Correspondence to} Dr Cassandra Bruce-Brand Anatomical Pathology, Stellenbosch University, PO Box 241, Cape Town, 8000, South Africa; cassandra.bruce-bran@ nhls.ac.za

Received 7 May 2020 Revised 27 May 2020 Accepted 28 May 2020 Published Online First 26 June 2020

Check for updates

(C) Author(s) (or their employer(s)) 2020. No commercial re-use. See rights and permissions. Published by BMJ.

\section{To cite: Bruce-}

Brand C, Schneider JW,

Schubert P. J Clin Pathol

2020:73:697-705.

\section{ABSTRACT}

Context Rosai-Dorfman disease is an uncommon histiocytic disorder most frequently presenting as bilateral cervical lymphadenopathy in children and young adults. Extranodal disease occurs in a significant proportion of patients. It has been recently classified as part of the 'R group' of histiocytoses by the Histiocyte Society in 2016. Cutaneous Rosai-Dorfman disease is regarded as a separate disease entity that falls into the 'C group' of histiocytoses according to this classification system. The pathogenesis was previously poorly understood; however, recent evidence demonstrating clonality in a subset of cases raises the possibility of a neoplastic process. A possible association with IgG4related disease remains controversial.

Objectives To provide a comprehensive review of Rosai-Dorfman disease, including nodal, extranodal and cutaneous forms, with a particular emphasis on new insights into the possible clonal nature of the disease; to discuss the recently revised classification of the histiocytoses by the Histiocyte Society; and to summarise the findings from the literature regarding the controversial association with lgG4-related disease.

Data sources This review is based on published peerreviewed English literature.

Conclusions Classic Rosai-Dorfman disease, which may be sporadic or familial, is considered a separate entity from cutaneous disease, which is reflected in the revised classification of histiocytoses. An increase in lgG4-positive plasma cells may be seen in Rosai-Dorfman disease. This finding in isolation is of limited significance and should be interpreted with caution. Studies investigating the molecular profile of the disease show that in at least a subset of cases the disease is a clonal process. The classification of Rosai-Dorfman disease is therefore likely to change as our understanding of the aetiopathogenesis evolves

Rosai-Dorfman-Destombes disease (RDD) is a rare histiocytic disorder described by Destombes in 1965 and later by Rosai and Dorfman in 1969 as 'sinus histiocytosis with massive lymphadenopathy' and previously classified by the Working Group of the Histiocyte Society of 1987 as a non-Langerhans cell (LC) histiocytosis. ${ }^{1-3}$ This same society has recently reclassified the histiocytoses based on new insights into the pathological, genetic and molecular features of these disorders. In this new classification, RDD now forms part of the 'R group' of histiocytoses, which includes familial RDD, sporadic RDD and other miscellaneous non-cutaneous, non-LC histiocytoses. ${ }^{4}$ Cutaneous RDD is classified separately as part of the 'C group' of histiocytoses. ${ }^{4}$ The diagnosis of RDD in the classic nodal form can usually be made with ease on routine H\&E stained sections with a small panel of immunohistochemical markers. Extranodal forms or cases in which there is extensive fibrosis or scant emperipolesis may pose diagnostic challenges. Immunohistochemistry is an essential part of the work-up, as Langerhans cell histiocytosis (LCH) and other neoplastic histiocytoses must be excluded. Recent evidence shows some degree of overlap with IgG4-related disease, although this remains controversial.

\section{AETIOPATHOGENESIS}

The aetiopathogenesis of RDD is poorly understood. It has been previously perceived to be a reactive, non-neoplastic histiocytic disorder that lacks clonality and was therefore not included in the latest (2017) WHO Classification of Tumours of Haematopoietic and Lymphoid Tissues. Evidence in support of a clonal nature of at least a subset of cases of RDD has recently come to light and is summarised here.

Kinase mutations have been recently described in nodal and extranodal (but not cutaneous) RDD, including mutations in $A R A F,{ }^{5} M A P 2 K 1,{ }^{67} N R A S^{5}$ and KRAS. ${ }^{5{ }^{6-10}} \mathrm{Up}$ to $33 \%$ of cases of RDD showed KRAS or MAP2K1 mutations in one study, indicating that a subset of cases may indeed be clonal. ${ }^{6}$ A 2019 publication in which targeted DNA/ RNA sequencing and whole exome sequencing were performed on 17 cases of RDD showed kinase driver mutations involving KRAS (4 of 17), MAP2K1 ( 2 of 17), NRAS (1 of 17), ARAF (1 of 17) and CSF1R (1 of 17). ${ }^{11}$ In addition, alterations in genes involved in intracellular trafficking (SNX24), transcriptional regulation (CIC, INTS2, SFR1, BRD4, $P H O X 2 B)$, cell cycle regulation (PDS5A, MUC4), DNA mismatch repair (ERCC2, LATS2, BRCA1, $A T M)$ and the ubiquitin proteasome pathway (USP35) were demonstrated. ${ }^{11}$

BRAF V600E mutations are described in histiocytic neoplasms such as $\mathrm{LCH}^{12}$ and Erdheim-Chester disease (ECD), ${ }^{13} 14$ and have been sought in RDD (see table 1). Ninety-one cases of RDD which show an absence of BRAF V600E mutations were found in the literature. $.^{13} 15-18$ Three cases of BRAF mutations have however been recently described. ${ }^{17} 1920$ Fatobene $e \mathrm{al}^{17}$ confirmed the presence of a BRAF V600E mutation in a single case of nodal RDD using multiplex picodroplet digital PCR. This mutation was not detected by pyrosequencing by the same authors. ${ }^{17}$ Mastropolo et $a l^{20}$ also demonstrated a BRAF V600E mutation in systemic mixed RDD and LCH. Anti-BRAF V600E immunohistochemistry was strongly positive in both RDD and $\mathrm{LCH}$, and BRAF p.V600E mutation was detected on peripheral blood mononuclear cells. ${ }^{20}$ Richardson $e t a l^{19}$ demonstrated a single somatic pathogenic mutation in exon 12 of the BRAF gene (p.486-491del) 
Table 1 Summary of RDD cases assessed for BRAF mutations

\begin{tabular}{|c|c|c|c|}
\hline Reference & Cases examined $(\mathrm{n})$ & Method of assessment & $B R A F$ mutation found \\
\hline Chakraborty et al ${ }^{15}$ & 4 & qPCR, whole exome sequencing, AmpliSeq & None \\
\hline Go et $a l^{16}$ & 5 & qPCR Sanger sequencing, PNAcqPCR & None \\
\hline Haroche et $a l^{13}$ & 23 & Pyrosequencing-PyroMark Q24 (QIAGEN) & None \\
\hline Fatobene et a $l^{17}$ & 13 & pddPCR & BRAF V600E (1 case) \\
\hline Cohen Aubart et al ${ }^{18}$ & 47 & Pyrosequencing & None \\
\hline Richardson et a $\left.\right|^{19}$ & 1 & NGS and Sanger sequencing & $\begin{array}{l}\text { BRAF variant-deletion in the } \beta 3-\alpha C \text { loop of the } \\
\text { kinase domain in exon } 12\end{array}$ \\
\hline Total & 94 & - & $\begin{array}{l}2 \text { (BRAF V600E) } \\
1 \text { (BRAF variant) }\end{array}$ \\
\hline
\end{tabular}

NGS, next generation sequencing; PBMCs, peripheral blood mononuclear cells; pddPCR, picodroplet digital PCR; PNAcqPCR, peptide nucleic acid clamp PCR; qPCR, quantitative

PCR; RDD, Rosai-Dorfman-Destombes disease.

in a single central nervous system case of RDD. No data on the molecular profile of cutaneous RDD could be found. In the series of 21 cases published by Garces et al, ${ }^{6}$ the presence of KRAS and/or MAP2K1 mutations was associated with a younger age $(\mathrm{p}=0.0251)$, head and neck site $(\mathrm{p}=0.0009)$ and multifocal disease $(p=0.0256)$.

Despite the expression of S100, the cell of origin is currently believed to be activated macrophages rather than dendritic cells. $^{21}$ Various viral agents, such as human herpesvirus 6, parvovirus B19 and Epstein-Barr virus, have been investigated as potential inciting agents, but studies have failed to establish a causative link. ${ }^{22-24}$

\section{CLASSIFICATION}

The disorders recently classified as part of the ' $\mathrm{R}$ group' of histiocytoses are summarised in figure $1 .{ }^{4}$ Sporadic RDD is the most common form and includes the classic nodal form, extranodal RDD, neoplasia-associated RDD and immune disease-associated RDD. ${ }^{4}$ Neoplasms associated with RDD include lymphomas, ${ }^{25-42}$ leukaemias, ${ }^{43-45}$ malignant histiocytoses, ${ }^{46} 47 \mathrm{LCH}^{48-51}$ and $\mathrm{ECD}^{52}$ (see table 2). Systemic lupus erythematosus, idiopathic juvenile arthritis, autoimmune haemolytic anaemia and HIV are among the immune disorders that are associated with RDD. ${ }^{34} 53$

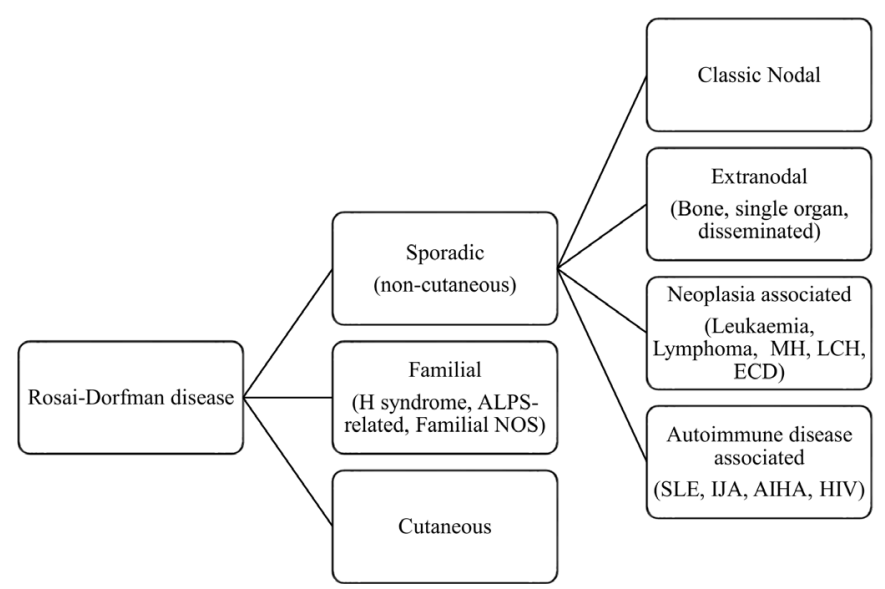

Figure 1 Schematic classification of Rosai-Dorfman disease according to the Histiocyte Society. ${ }^{4}$ AlHA, autoimmune haemolytic anaemia; ALPS, autoimmune lymphoproliferative syndrome; ECD, ErdheimChester disease; IJA, idiopathic juvenile arthritis; LCH, Langerhans cell histiocytosis; MH, malignant histiocytoses; NOS, not otherwise specified; $\mathrm{SLE}$, systemic lupus erythematosus.
Familial RDD includes H syndrome (Faisalabad syndrome), an autosomal recessive genetic syndrome caused by mutations in the SLC29A3 gene, in which up to $20 \%$ of cases demonstrate nodal (19 of 79 cases) and/or extranodal (skin (23 of 79 cases) and nasal cavity ( 2 of 79 cases)) RDD. ${ }^{54-63}$ The syndrome is characterised by hyperpigmentation, hypertrichosis, hepatosplenomegaly, hearing loss, heart anomalies, hypogonadism, short stature (low height), hyperglycaemia and hallux valgus. ${ }^{62}$ Also included in familial RDD is FAS deficiency or autoimmune lymphoproliferative syndrome (ALPS)-related RDD caused by germline mutations in TNFRSF6. ${ }^{64}$ Forty-one per cent (18 of 44) of patients with confirmed ALPS were found to have nodal RDD in one study. ${ }^{64}$ Only one case of extranodal RDD, involving the spleen, has been described in this setting. ${ }^{47}$

Cutaneous RDD is classified under the ' $\mathrm{C}$ group' of histiocytoses. ${ }^{4}$ This group is further divided into xanthogranuloma and non-xanthogranuloma families (into which cutaneous RDD falls). ${ }^{4}$ Cutaneous RDD demonstrates unique epidemiological and clinical features and is therefore classified separately from other forms of RDD. ${ }^{65}$ Distinction from the xanthogranuloma family (S100-negative) is important and is discussed further in the Differential diagnosis section.

\section{CLINICAL FEATURES}

Classic RDD presents with massive bilateral painless cervical lymphadenopathy with associated fever, loss of weight and night sweats. $^{266}$ It affects predominantly children and young adults with an average age of onset of 20.6 years, and occurs more commonly in African patients with a slight male predominance

\begin{tabular}{lcl}
\hline Table 2 & Neoplasms associated with RDD & \\
\hline Neoplasms associated with RDD & Cases reported (n) & Reference \\
\hline Lymphoma & 34 & $25-42$ \\
Leukaemia & 3 & $43-45$ \\
LCH & 12 & $48-51$ \\
MH & 2 & 4647 \\
ECD & 1 & 52 \\
\hline
\end{tabular}

Types of lymphoma include Hodgkin's lymphoma-classic (8) 252635 and nodular lymphocyte predominant $(8)^{35} 36$ and non-Hodgkin's lymphoma-follicular $(2),{ }^{25} \mathrm{~T}$ cell (3), ${ }^{29-31}$ small lymphocytic lymphoma (2), ${ }^{3537}$ Mantle cell (1), ${ }^{38}$ marginal zone lymphoma (3), ${ }^{35} 3940$ diffuse large B cell lymphoma (4), ${ }^{27} 284142$ mycosis fungoides $(1)^{32}$ and other (large cell immunoblastic and small non-cleaved, 2). ${ }^{33} 34$ Types of leukaemia include acute myeloid leukaemia $(1)^{43}$ and acute lymphoblastic leukaemia (2). ${ }^{44} 45$

ECD, Erdheim-Chester disease; LCH, Langerhans cell histiocytosis; MH, malignant histiocytoses; RDD, Rosai-Dorfman-Destombes disease. 
(male to female ratio of 1.4). ${ }^{34}$ Inguinal, retroperitoneal and mediastinal lymph nodes may also be involved. ${ }^{466}$ Extranodal disease is seen in over $40 \%$ of cases and may rarely occur in the absence of nodal disease, usually in older patients with different demographics. ${ }^{3453656768}$ Common extranodal sites of involvement include the skin $(10 \%),{ }^{69} 70$ nasal cavity $(11 \%),{ }^{34}$ bone $(5 \%-10 \%),{ }^{3471}$ orbital tissue $(11 \%)^{34}$ and central nervous system (5\%, predominantly dural) ${ }^{67}{ }^{72-74}$ Bone involvement is seen as lytic lesions with well-defined sclerotic margins on radiography and is associated with nodal disease in $10 \%$ of cases. ${ }^{34175}$ Central nervous system involvement may mimic meningioma clinically and is usually not associated with nodal disease. ${ }^{6774}$ An elevated erythrocyte sedimentation rate, leucocytosis, hypergammaglobulinaemia and autoimmune haemolytic anaemia may be observed on laboratory studies. ${ }^{53}$

Cutaneous RDD presents in patients with an older mean age (43.5 years) than nodal RDD, a higher proportion of female patients (2:1 ratio) and a higher proportion of Asian and white patients. ${ }^{65}$ These patients typically lack an association with systemic or extracutaneous disease, and the disease process tends to remain localised despite long-term follow-up. ${ }^{65}{ }^{68}$ In a series of 25 cases from China, the majority of patients (80\%) presented with papulonodular lesions. ${ }^{68}$ Other presentations described include indurated plaques, tumour-like lesions, acneiform lesions and eruptive xanthoma-like lesions. ${ }^{687677}$

\section{PATHOLOGY FINDINGS}

\section{Gross features}

Lymph nodes involved by RDD are enlarged and matted together forming firm multinodular masses with a yellow-white appearance on cut section. ${ }^{234}$ Fibrosis of the capsule may be evident. ${ }^{2}$

\section{Microscopic features}

The striking histological finding in RDD is an enlarged node with a low power appearance of extensive sinusoidal expansion (figure 2). ${ }^{2}$ In more advanced cases there is effacement of the nodal architecture with a diffuse infiltrate of histiocytes. The cortex comprises numerous activated B cells and mature plasma cells with few follicles which, together with the pale histiocytes, give the appearance of alternating dark and light zones.

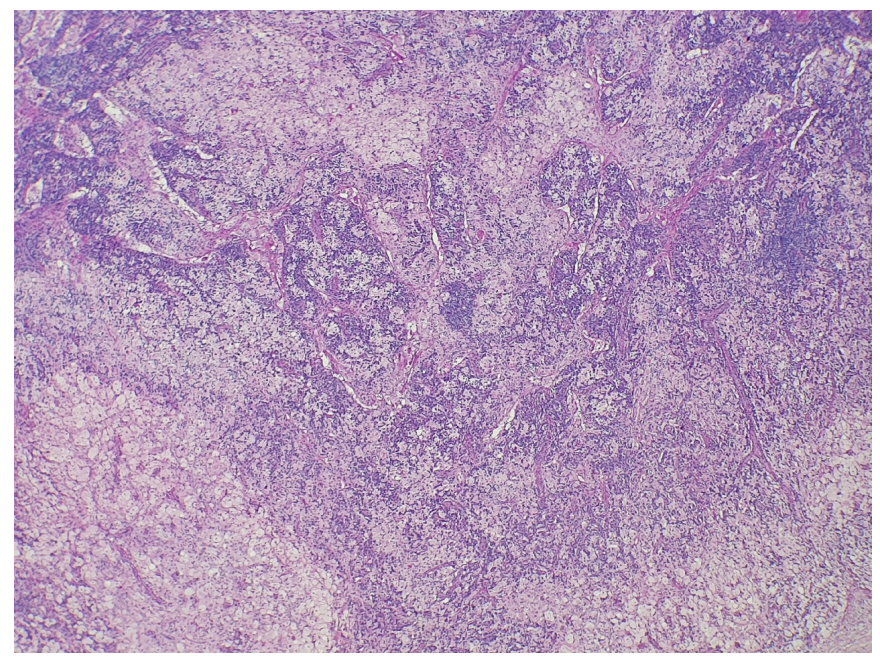

Figure $2 \mathrm{H} \& \mathrm{E}$ 40x. Low power view of nodal Rosai-Dorfman disease showing alternating light and dark areas. The dark areas comprise an admixture of lymphocytes and plasma cells. The light areas comprise the characteristic pale pink histiocytic cells of Rosai-Dorfman disease.

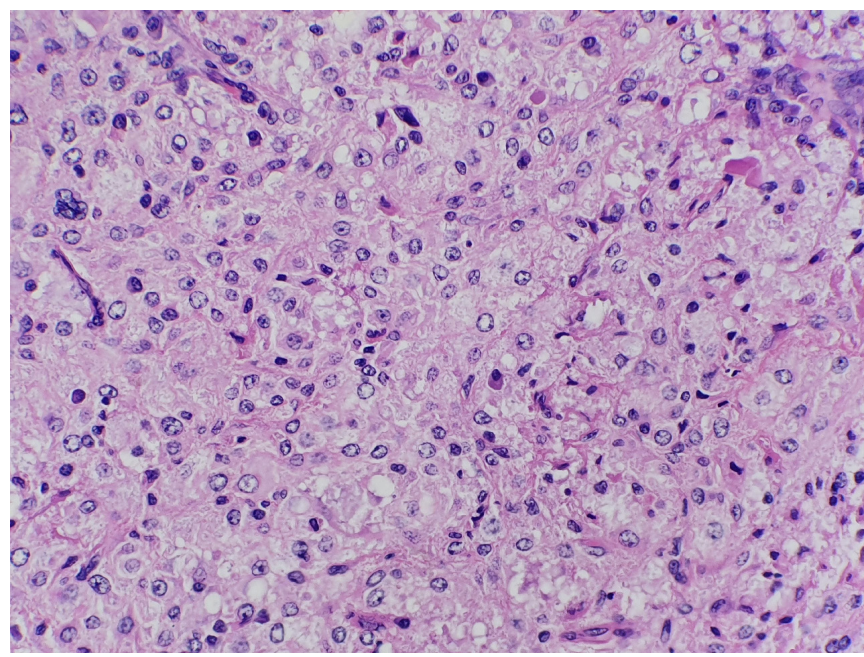

Figure 3 H\&E 200x. Nodal Rosai-Dorfman disease showing sheets of large pale pink cells with wispy cytoplasm and vesicular nuclei.

The sinusoids contain numerous large histiocytic cells with smooth contoured hypochromatic nuclei, small distinct centrally placed round nucleoli and ill-defined, pale, wispy cytoplasm (figure 3). ${ }^{34}$ Multinucleation, atypia and rare mitotic figures may be seen; however, the majority of cells usually retain smooth nuclear contours and abundant pale cytoplasm. Emperipolesis, a useful but not specific feature, is seen as intact haematolymphoid cells within a vacuole or floating freely in the cytoplasm of the histiocytes (figure 4). Neutrophils may be seen in the background (figure 5), occasionally forming micro-abscesses, and eosinophils are typically absent. Marked sclerosis with a storiform architecture and lobulation may be seen (figure 6). Extranodal disease mimics nodal RDD closely but may display more prominent lymphoid follicles with germinal centres, fibrosis, sclerosis, fewer histiocytes and more subtle emperipolesis (figure 7). Emperipolesis is not a requirement for the diagnosis and is often inconspicuous at extranodal sites in particular. ${ }^{69} \mathrm{~A}$ careful search for coexisting pathology in nodal disease is required as RDD can occur with lymphoma, ECD and LCH, as described above. In such cases the specimen should demonstrate RDD in more

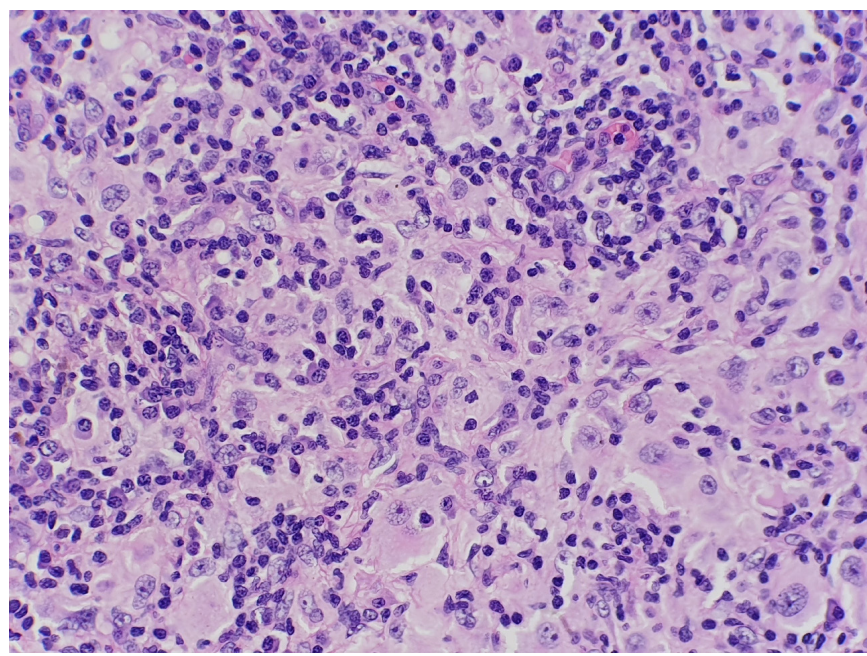

Figure 4 H\&E 200×. Nodal Rosai-Dorfman disease showing characteristic cells with abundant wispy cytoplasm and admixed inflammatory cells including lymphocytes and plasma cells.

Emperipolesis is seen. 


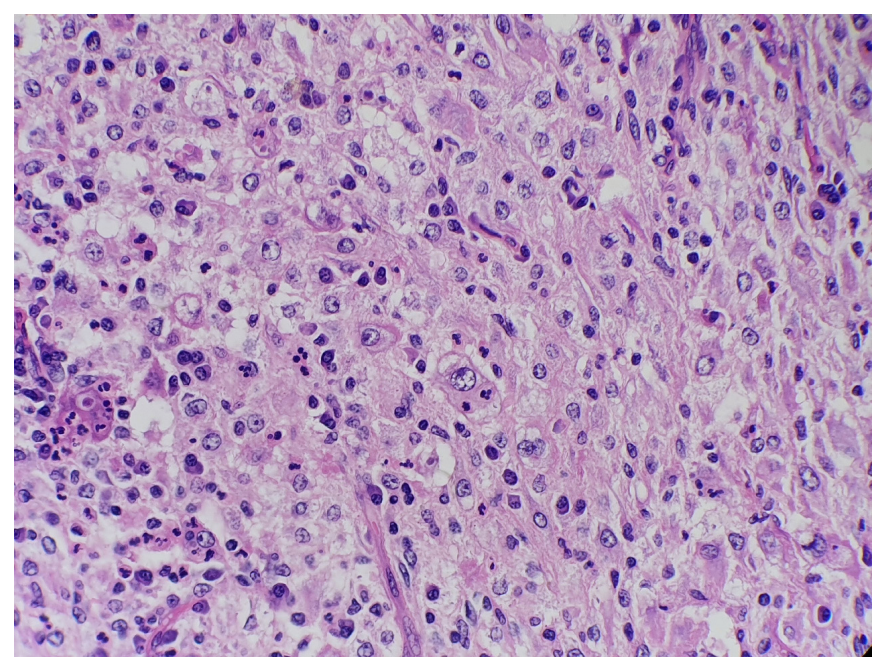

Figure 5 H\&E 200x. Nodal Rosai-Dorfman disease showing characteristic cells with emperipolesis of other inflammatory cells. Neutrophils are evident in this image.

than $10 \%$ of the tissue to constitute a diagnosis of neoplasiaassociated RDD. ${ }^{69}$

Cutaneous RDD is typically a dermal-based lesion, sometimes involving the dermis and subcutaneous tissue (figure 8). ${ }^{65}$ The overlying epidermis may show acanthosis, increased basal keratinocyte pigmentation, ulceration or an epidermal collarette. The lesion is typically nodular and poorly circumscribed with infiltration into adjacent tissue. The typical histiocytic cells with emperipolesis as described above are characteristic. These cells may form bands or sheets giving a light and dark zonal appearance as described above or may be haphazardly distributed with more of a starry-sky low power appearance (figure 9). Plasma cells and neutrophils are often present with formation of micro-abscesses.

\section{Features seen on fine needle aspiration}

Fine needle aspirates show a heterogeneous population of lymphoid cells, including lymphocytes, plasma cells and scattered large histiocytes with oval vesicular nuclei and conspicuous nucleoli. ${ }^{78}$ The cytoplasm of the histiocytes is abundant and wispy and emperipolesis may be seen (figure 10).

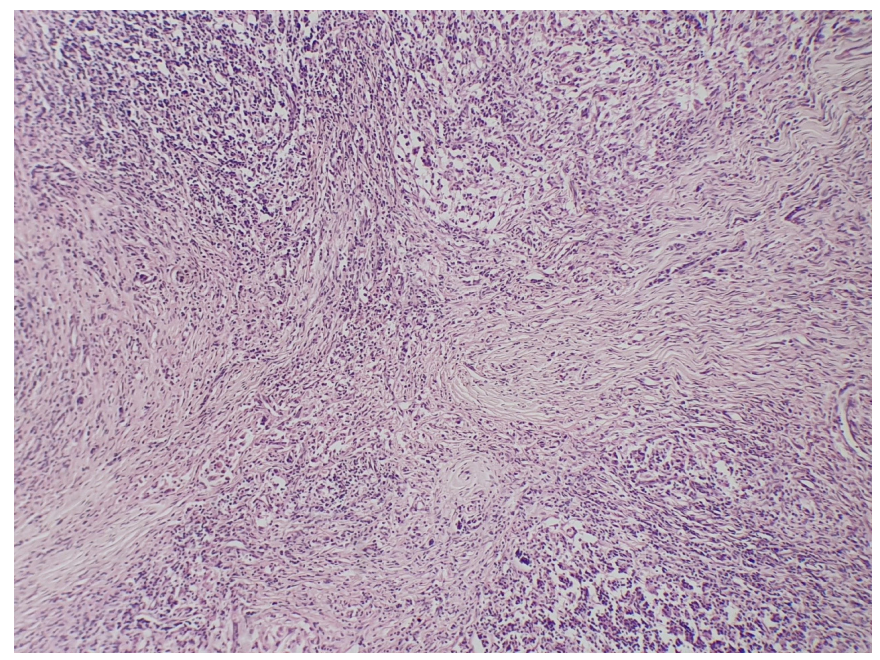

Figure 6 H\&E 100x. Nodal Rosai-Dorfman disease showing marked fibrosis which may be storiform.

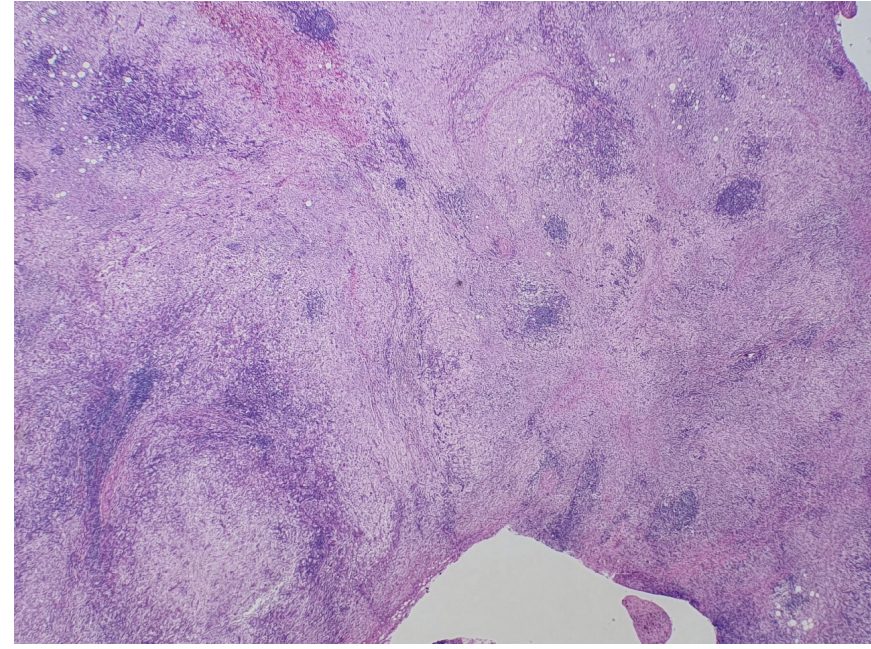

Figure 7 H\&E 20x. Extranodal Rosai-Dorfman disease showing sheets of pale histiocytes with scattered lymphoid aggregates and follicles.

\section{ANCILLARY STUDIES}

The histiocytes are S100, CD68 and CD163 positive and are by definition CD1a and langerin (CD207) negative, thereby excluding $\mathrm{LCH}$. The S100 stain often highlights the emperipolesis (figure 11). The plasma cell population in the cortex will stain with plasma cell markers (CD38, CD138 and MUM1) and may demonstrate abundant IgG4-positive plasma cells (figure 12). ${ }^{79}$ Based on consensus expert opinion, the Histiocyte Society recommends that all cases of RDD be evaluated for IgG4positive plasma cells (grade D2 evidence) (see the the Differential diagnosis section for further discussion on this issue). ${ }^{4}$

\section{DIFFERENTIAL DIAGNOSIS}

Perhaps the most important differential diagnosis of RDD is that of LCH. A diagnosis of RDD by definition requires the exclusion of LCH by negative CD1a or CD207 staining of the histiocytic infiltrate. Other morphological clues to this differential are the absence of an eosinophilic infiltrate in RDD, the characteristic elongated grooved nuclear features of $\mathrm{LCH}$ and the absence of a prominent plasma cell component in LCH. Of note, S100 positivity is observed in both RDD and LCH. RDD may be associated

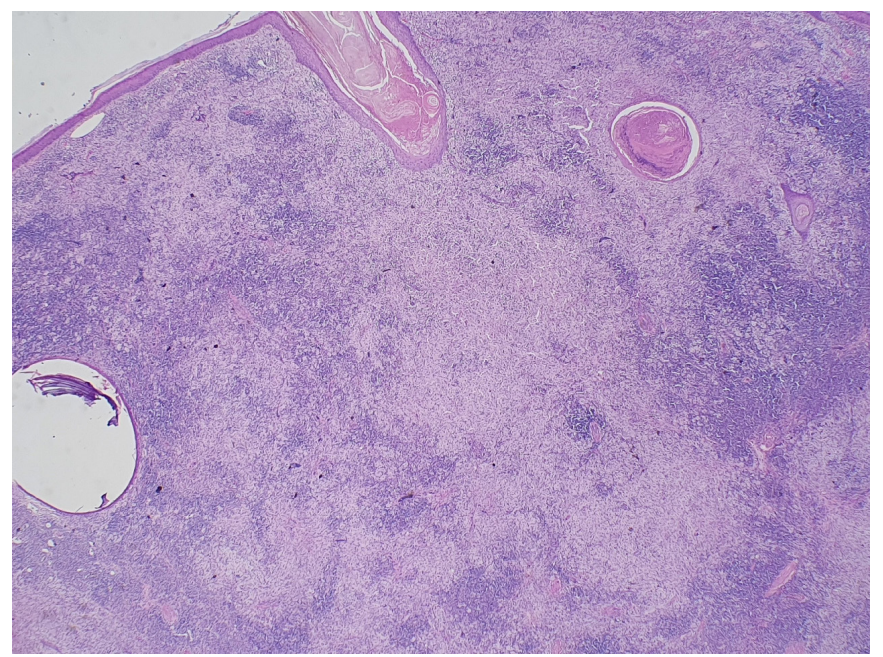

Figure 8 H\&E 20x. Cutaneous Rosai-Dorfman disease showing expansion of the dermis by an infiltrate of large pale cells admixed with lymphocytes. 


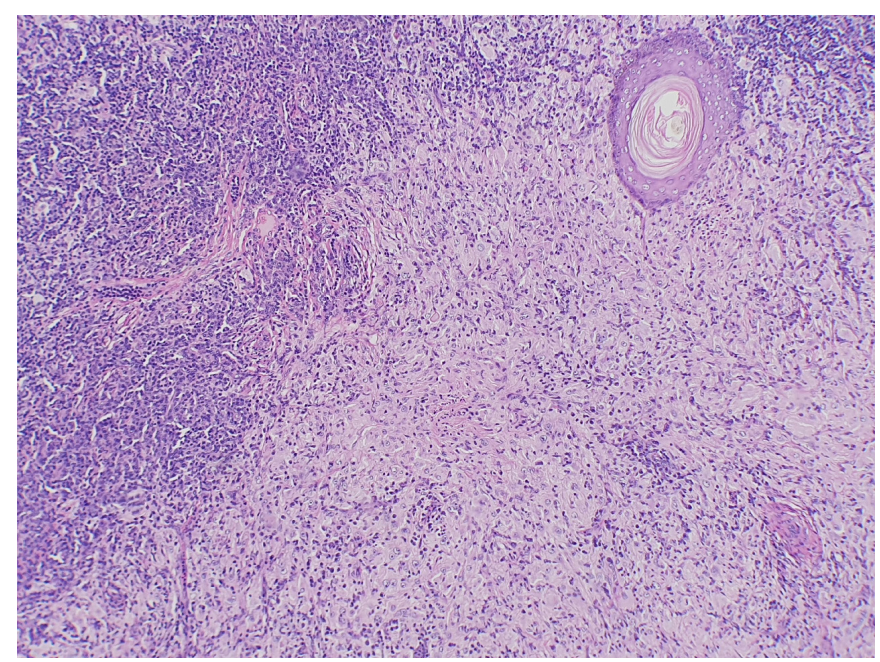

Figure 9 H\&E 100x. Cutaneous Rosai-Dorfman disease showing sheets of pale cells with bands of lymphocytes giving a light and dark zonal appearance.

with LCH as discussed previously. Two distinct populations of cells with different immunohistochemical staining (one CD1apositive, \pm S100; and one CD1a-negative, + S100) would need to be demonstrated to make this diagnosis.

Nodal RDD may also simulate other conditions with a prominent sinusoidal pattern, such as sinus histiocytosis, anaplastic large cell lymphoma (ALCL), metastatic carcinoma and malignant melanoma. This can usually be resolved with immunohistochemistry and close attention to the H\&E morphology. Sinus histiocytosis lacks the characteristics described above of the typical RDD histiocytic cells and would be negative for S100. ALCL will demonstrate more nuclear pleomorphism with typical hallmark cells which will be CD30-positive. Metastatic carcinoma and melanoma will not usually show emperipolesis and carcinoma will be positive with pan-cytokeratin markers. Melanoma will be S100-positive but will also stain positive with HMB45, Melan-A and SOX10. Other disorders such as Gaucher disease, Whipple disease and Hodgkin's lymphoma may enter the differential diagnosis in nodal disease. Gaucher disease demonstrates histiocytes filled with finely fibrillar, tissue paper-like cytoplasm due to accumulation of sphingolipids. The nuclei typically have indistinct nucleoli and lack emperipolesis.

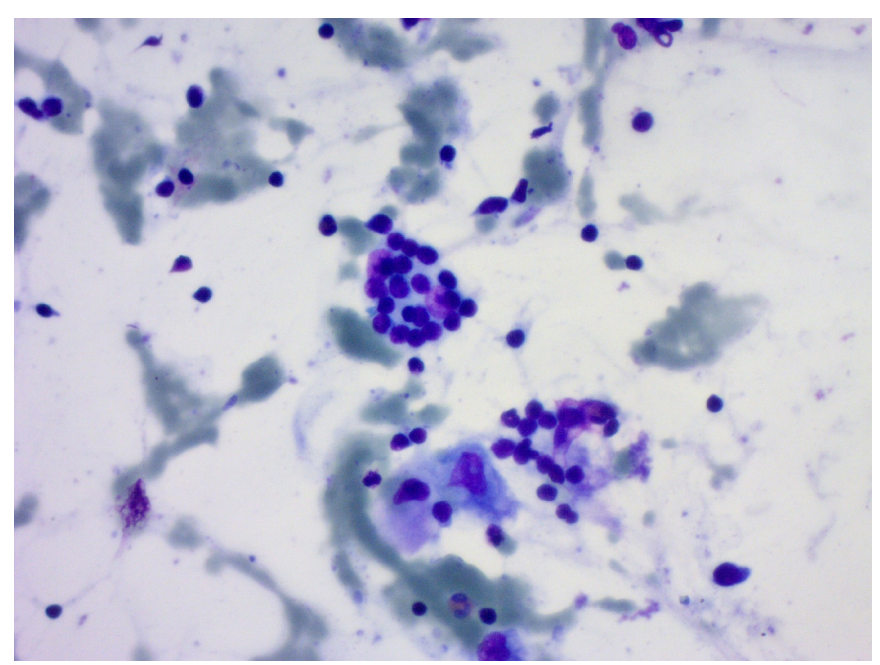

Figure 10 Giemsa stain 1000× under oil. Large histiocyte with emperipolesis in an aspirate of a cervical lymph node.

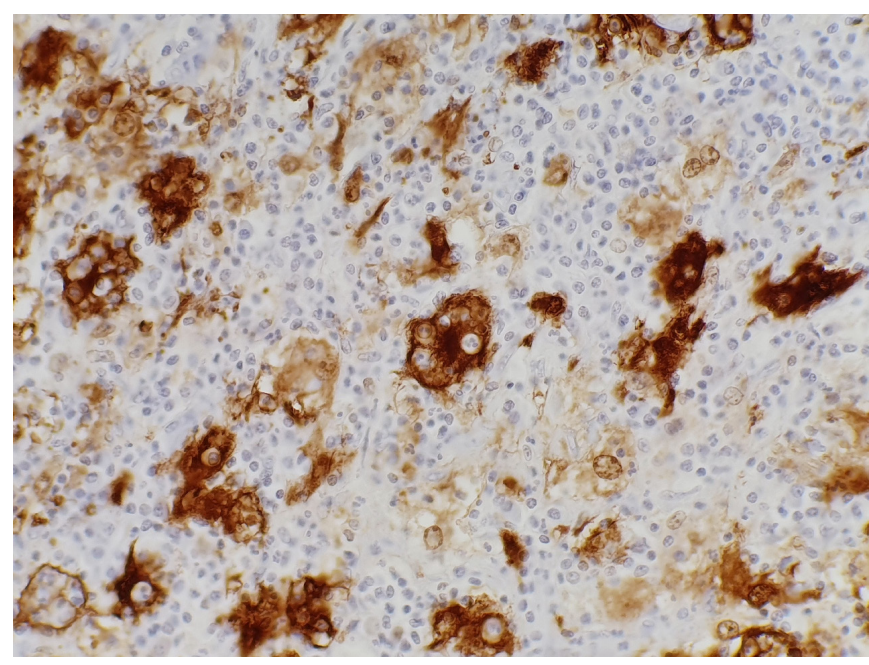

Figure 11 S100 protein immunohistochemical stain 200x. The S100 highlights the histiocytes as well as the emperipolesis (lack of staining of the inflammatory cells within the cytoplasm of the histiocytes).

In Whipple disease the macrophages are packed with periodic acid-schiff positive diastase-resistant bacilli and nodal involvement is typically mesenteric. Classic Hodgkin's lymphoma will usually show more typical Reed-Sternberg or Hodgkin's cells with macronucleoli, lacks S100 positivity, and the large cells stain positive with CD30 and CD15 with a characteristic Golgi pattern of staining.

Within the head and neck region rhinoscleroma, granulomatosis with polyangiitis and extranodal natural killer/T cell lymphoma may be considered. Again, close attention to the H\&E morphology with positive S100 staining of the histiocytes can resolve most of these differentials.

Cutaneous involvement must be distinguished from juvenile xanthogranuloma (JXG). JXG is characterised by macrophages and spindled cells with scattered Touton-type multinucleated giant cells, negativity for S100 and lack of emperipolesis. The storiform sclerosis and presence of plasma cells that may be seen, particularly in cutaneous RDD, raise the differential diagnosis of IgG4-related sclerosing disease, which is discussed further in the next section.

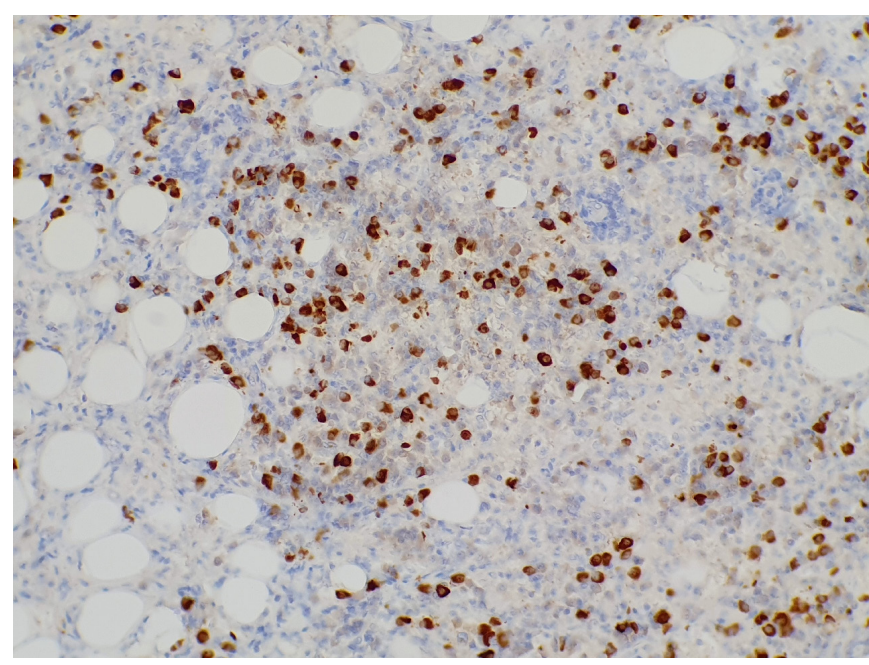

Figure $12 \operatorname{lgG} 4$ immunohistochemical stain 200x. Numerous plasma cells staining positive for lgG4 are highlighted in this case of RosaiDorfman disease. 
Table 3 Summary of findings of increased IgG4-positive plasma cells in RDD in the literature

\begin{tabular}{|c|c|c|c|c|c|}
\hline Reference & $\begin{array}{l}\text { Cases } \\
\text { examined (n) }\end{array}$ & $\begin{array}{l}\text { Mean number of IgG4- } \\
\text { positive cells/HPF }\end{array}$ & Mean $\operatorname{lgG} 4 / \operatorname{lgG}$ ratio & $\begin{array}{l}\text { Cases with } \\
\operatorname{lgG} 4: \lg \rightarrow>40 \%\end{array}$ & Anatomical sites of cases with $\operatorname{lgG} 4: \lg G>40 \%$ \\
\hline Kuo et al ${ }^{79}$ & 12 & 117 (range 21-204) & $34 \%$ (range $16 \%-51 \%$ ) & $3(25 \%)$ & Cutaneous \\
\hline Menon et a $\left.\right|^{80}$ & 70 & $103^{*}$ (range $\left.10-350\right)$ & $39 \% *$ (range $5 \%-97 \%$ ) & $12(17 \%)$ & $\begin{array}{l}\text { Lymph node (7), salivary gland (1)†, renal (1), } \\
\text { mesenteric (1), nasal (1), dural (1), subcutaneous (1) }\end{array}$ \\
\hline Zhang et $a l^{81}$ & 26 & $\begin{array}{l}39.7 \text { nodal }( \pm 11) \\
22.5 \text { extranodal }( \pm 4.6)\end{array}$ & $\begin{array}{l}27.9 \% \text { nodal } \\
33.7 \% \text { extranodal }\end{array}$ & $8(30 \%)$ & Nodal (5), extranodal (3) \\
\hline Shrestha et $a^{82}$ & 8 & 66.8 (range $0-224$ ) & $27.5 \%$ (range $0 \%-70 \%$ ) & $3(37.5 \%)$ & Nodal (2), soft tissue (1) \\
\hline $\begin{array}{l}\text { Roberts and } \\
\text { Attanoos }^{84}\end{array}$ & 1 & Between 11 and 30 & Not provided & - & Lung \\
\hline El-Kersh et al ${ }^{83}$ & 1 & $\begin{array}{l}\text { 'Significant' — not further } \\
\text { specified }\end{array}$ & Not provided & - & Lung \\
\hline Richter et $\left.a\right|^{87}$ & 1 & $\begin{array}{l}\text { 'Not increased'—-not further } \\
\text { specified }\end{array}$ & Not provided & - & Heart \\
\hline Liu et $a l^{86}$ & 29 & 13.2 (range $5.2-32.6$ ) & $21 \%$ (range $11 \%-34 \%$ ) & $3(10 \%)$ & Nodal, thyroid, skin \\
\hline Chen and Lee ${ }^{88}$ & 1 & 121 & $33 \%$ & - & Parotid \\
\hline
\end{tabular}

HPF defined as $0.06 \mathrm{~mm}^{2}$ by all reports.

The lgG4 to $\lg G$ ratio of more than $40 \%$ is included based on the $\lg G 4$ consensus guidelines.

* Mean calculated from the data available for the 29 cases that had elevated levels of IgG4-positive plasma cells.

tOne case had lymph node and salivary gland involvement, with both sites showing IgG4 to lgG ratio $>40 \%$.

HPF, high power field; RDD, Rosai-Dorfman-Destombes disease.

\section{The link to IgG4-related disease}

RDD may share some morphological features with IgG4related disease, such as storiform fibrosis and abundant plasma cells, thereby raising this condition as a possible differential diagnosis. This is particularly true in cutaneous disease, which often shows marked sclerosis with a storiform architecture. In 2009 Kuo et $a l^{79}$ documented a possible association between RDD and IgG4-related disease by demonstrating high levels of IgG4-positive plasma cells in cases of cutaneous RDD. Of the 12 cutaneous cases assessed in this study, 11 showed more than 30 IgG4-positive cells per high power field (HPF), with a mean IgG4 to IgG ratio of $34 \%$ (see table 3 ). ${ }^{79}$ This was followed by other studies which showed similar findings of abundant IgG4positive plasma cells with raised IgG4 to IgG ratios in RDD at nodal and extranodal sites (table 3). ${ }^{79-82}$ Two pulmonary cases of $\mathrm{RDD}$ are also reported to have shown increased IgG4-positive plasma cells; however, the exact number of positive cells and the IgG4 to IgG ratio were not published and were scored as 'significant ${ }^{\text {83 }}$ and 'score of 2' (11-30 IgG4-positive plasma cells/ HPF).$^{84}$ These findings were not corroborated in other studies of RDD and the association between these disorders has not been widely accepted. ${ }^{85}$ Liu $e t a l^{86}$ described only 3 of 29 cases with IgG4 to IgG ratio of more than $40 \%$. Richter et $a l^{87}$ and Chen and Lee ${ }^{88}$ did not find an increase in IgG4-positive plasma cells in one parotid and one cardiac case.

In 2012 a consensus statement on the pathology of IgG4related disease was published. ${ }^{85}$ Histological criteria for the diagnosis of IgG4-related disease (storiform fibrosis, obliterative phlebitis and a dense lymphoplasmacytic infiltrate) with specific cut-off points for the number of IgG4-positive plasma cells by site were defined. A three-tiered diagnostic terminology based on pathological features was proposed, including 'histologically highly suggestive of IgG4-related disease', 'probable histological features of IgG4-related disease' and 'insufficient histopathological evidence of IgG4-related disease' ${ }^{85}$ The consensus statement concludes with minimal criteria required to propose a new diagnosis of IgG4-related disease, which includes the histological criteria as well as raised serum IgG4 levels, response to glucocorticoid therapy, and other organ involvement consistent with IgG4-related disease. ${ }^{85}$
A diagnosis of IgG4-related disease thus requires clinical, serological and histological evidence and not one of these in isolation is sufficient. They further state that interpretation of isolated increased IgG4-positive plasma cells should be made with caution as this is a relatively non-specific finding that can be seen in many inflammatory conditions. ${ }^{85}$

In 2015 an expert panel published a consensus guidance statement on the management and treatment of IgG4-related disease in which they state that the most accurate assessment of IgG4-related disease is based on full clinical history, physical examination, selected laboratory investigations and appropriate radiology studies. ${ }^{89}$ The panel states that neither clinical or pathological features alone are sufficient to make a diagnosis and that disorders that mimic IgG4-related disease must be rigorously excluded. ${ }^{89} \mathrm{RDD}$ is listed as one of the disorders that may mimic IgG4-related disease clinically or histologically.

It is clear from these guidelines that an increased number of IgG4-positive plasma cells in isolation has no diagnostic utility and that IgG4 immunohistochemical staining should be performed and interpreted with great caution. It has however been recommended by the Histiocyte Society in the revised classification of the histiocytoses that all cases of RDD should be evaluated for IgG4-positive plasma cell infiltration (based on expert opinion: grade D2 evidence). ${ }^{4}$ No further guidelines are provided on how these results should be interpreted, and to our knowledge no such guidelines within the context of RDD currently exist.

In our practice, based on the recommendation of the Histiocyte Society, an IgG4 immunohistochemical stain is performed on all cases. Three $\times 40$ fields ( 22 field number eyepiece) with the highest number of positive staining cells are counted and an average calculated as suggested in the consensus statement. ${ }^{85}$ The result is documented as the number of IgG4-positive plasma cells per HPF. Further information regarding this calculation can be seen in the consensus guidelines. ${ }^{85}$ Based on the clear guidelines provided for the diagnosis of IgG4-related disease, a comment is added that the significance of this result in isolation without other clinical, serological or radiological evidence for IgG4-related disease is uncertain and that isolated increased numbers of IgG4-positive plasma cells may be seen in RDD. 


\section{CURRENT TREATMENT AND PROGNOSIS}

Sporadic RDD is usually self-limited and has a good outcome, with spontaneous remission reported in up to $50 \%$ of cases..$^{90} \mathrm{Up}$ to $10 \%$ of patients may die of their disease due to direct complications, infections and amyloidosis. ${ }^{34} 90$ Consensus recommendations for the work-up and management of RDD were published in 2018 and are beyond the scope of this review. ${ }^{69}$ Briefly summarised here, observation is indicated in patients with uncomplicated adenopathy and asymptomatic cutaneous disease. ${ }^{69}$ Surgical excision may be indicated in unifocal extranodal disease or for symptomatic airway, cranial, spinal or sinus disease ${ }^{69}$ Those with multifocal irresectable extranodal disease may require systemic therapy of which there is currently no standardised regimen. Systemic therapies include corticosteroids, sirolimus, radiotherapy, chemotherapy and immunomodulatory therapy. ${ }^{69}$ Sufficient evidence is currently lacking to support firm associations between prognosis and underlying molecular alterations. The consensus recommendations advise targeted next generation sequencing for Mitogen-Activated Protein Kinase (MAPK) mutations in severe or refractory disease with consideration of targeted therapy if driver mutations are identified. ${ }^{69}$

\section{CONCLUSIONS}

Classic RDD is classified as part of the 'R group' of histiocytoses. Cutaneous RDD is considered distinct with different epidemiology and clinical features and falls into the ' $\mathrm{C}$ group' of histiocytoses. The diagnosis can be made by recognising the characteristic S100-positive histiocytes with emperipolesis that expand the sinusoids and impart a dark and light zonal appearance to the tissue. Diagnostic pitfalls include the presence of extensive fibrosis is some cases (particularly in cutaneous RDD), scant emperipolesis in extranodal disease and failure to exclude important differential diagnoses. It is currently recommended that all cases be evaluated for IgG4-positive plasma cells. Any reported increase in IgG4-positive plasma cells should be accompanied by a comment that this finding requires interpretation in conjunction with an appropriate clinical, serological and radiological context. Our understanding of the aetiopathogenesis of $\mathrm{RDD}$ is evolving. Although not currently classified as a neoplastic disorder, recent studies showing clonality in some cases have changed our understanding of the disease. Further characterisation of the spectrum of molecular alterations in RDD is required. The implications of these findings for prognosis and treatment purposes remain to be determined.

\section{Take home messages}

- RDD is classified as part of the ' $R$ group' of histiocytoses and includes classic nodal disease, extranodal disease, neoplasia associated and autoimmune associated disease. It may be sporadic or familial.

- Cutaneous RDD is classified separately as part of the 'C group' of histiocytoses and must be distinguished from juvenile xanthogranuloma.

- At least a subset of cases are clonal with mutations involving MAP2K1, KRAS, NRAS, ARAF and CSF1R. BRAF mutations are uncommon compared to Langerhans cell histiocytosis and Erdheim-Chester disease.

- An increase in IgG4 positive plasma cells should be documented but interpreted in context

\section{Handling editor Runjan Chetty.}

Contributors All authors have contributed to the production of this manuscript.
Funding The authors have not declared a specific grant for this research from any funding agency in the public, commercial or not-for-profit sectors.

Competing interests None declared.

Patient consent for publication Not required.

Provenance and peer review Not commissioned; externally peer reviewed.

ORCID iD

Cassandra Bruce-Brand http://orcid.org/0000-0003-0438-768X

\section{REFERENCES}

1 Destombes P. [Adenitis with lipid excess, in children or young adults, seen in the Antilles and in Mali. (4 cases)]. Bull Soc Pathol Exot Filiales 1965;58:1169-75.

2 Rosai J, Dorfman RF. Sinus histiocytosis with massive lymphadenopathy. A newly recognized benign clinicopathological entity. Arch Pathol 1969;87:63-70.

3 Writing Group of the Histiocyte Society. Histiocytosis syndromes in children. Lancet $1987 ; 1: 208-9$

4 Emile J-F, Abla O, Fraitag $S$, et al. Revised classification of histiocytoses and neoplasms of the macrophage-dendritic cell lineages. Blood 2016;127:2672-81.

5 Diamond EL, Durham BH, Haroche J, et al. Diverse and targetable kinase alterations drive histiocytic neoplasms. Cancer Discov 2016;6:154-65.

6 Garces S, Medeiros LJ, Patel KP, et al. Mutually exclusive recurrent KRAS and MAP2K1 mutations in Rosai-Dorfman disease. Mod Pathol 2017;30:1367-77.

7 Matter MS, Bihl M, Juskevicius D, et al. Is Rosai-Dorfman disease a reactive process? Detection of a MAP2K1 L115V mutation in a case of Rosai-Dorfman disease. Virchows Arch 2017;471:545-7.

8 Shanmugam V, Margolskee E, Kluk M, et al. Rosai-Dorfman disease harboring an activating KRAS K117N missense mutation. Head Neck Pathol 2016;10:394-9.

9 Lee LH, Gasilina A, Roychoudhury J, et al. Real-time genomic profiling of histiocytoses identifies early-kinase domain BRAF alterations while improving treatment outcomes. JCI Insight 2017;2:e89473.

10 Jacobsen E, Shanmugam V, Jagannathan J. Rosai-Dorfman Disease with Activating KRAS Mutation - Response to Cobimetinib. N Engl J Med 2017;377:2398-9.

11 Durham BH, Lopez Rodrigo E, Picarsic J, et al. Activating mutations in CSF1R and additional receptor tyrosine kinases in histiocytic neoplasms. Nat Med 2019;25:1839-42

12 Badalian-Very G, Vergilio J-A, Degar BA, et al. Recurrent BRAF mutations in Langerhans cell histiocytosis. Blood 2010;116:1919-23.

13 Haroche J, Charlotte F, Arnaud L, et al. High prevalence of BRAF V600E mutations in Erdheim-Chester disease but not in other non-Langerhans cell histiocytoses. Blood 2012;120:2700-3.

14 Emile J-F, Diamond EL, Hélias-Rodzewicz Z, et al. Recurrent RAS and PIK3CA mutations in Erdheim-Chester disease. Blood 2014;124:3016-9.

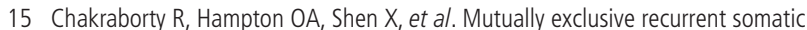
mutations in MAP2K1 and BRAF support a central role for ERK activation in LCH pathogenesis. Blood 2014;124:3007-15.

$16 \mathrm{Go} \mathrm{H}$, Jeon YK, Huh J, et al. Frequent detection of BRAF(V600E) mutations in histiocytic and dendritic cell neoplasms. Histopathology 2014;65:261-72.

17 Fatobene $\mathrm{G}$, Haroche J, Hélias-Rodzwicz Z, et al. BRAF V600E mutation detected in a case of Rosai-Dorfman disease. Haematologica 2018;103:e377-9.

18 Cohen Aubart F, Haroche J, De Risi T, et al. La maladie de Rosai-Dorfman-Destombes est une histiocytose inflammatoire polymorphe : étude phénotypique multicentrique de 47 patients. La Revue de Médecine Interne 2015;36:A40-1.

19 Richardson TE, Wachsmann M, Oliver D, et al. BRAF mutation leading to central nervous system Rosai-Dorfman disease. Ann Neurol 2018;84:147-52.

20 Mastropolo R, Close A, Allen SW, et al. BRAF-V600E-mutated Rosai-DorfmanDestombes disease and Langerhans cell histiocytosis with response to BRAF inhibitor. Blood Adv 2019;3:1848-53.

21 Middel P, Hemmerlein B, Fayyazi A, et al. Sinus histiocytosis with massive lymphadenopathy: evidence for its relationship to macrophages and for a cytokinerelated disorder. Histopathology 1999;35:525-33.

22 Levine PH, Jahan N, Murari P, et al. Detection of human herpesvirus 6 in tissues involved by sinus histiocytosis with massive lymphadenopathy (Rosai-Dorfman disease). J Infect Dis 1992;166:291-5

23 Mehraein $Y$, Wagner M, Remberger K, et al. Parvovirus B19 detected in Rosai-Dorfman disease in nodal and extranodal manifestations. J Clin Pathol 2006;59:1320-6.

24 Tsang WY, Yip TT, Chan JK. The Rosai-Dorfman disease histiocytes are not infected by Epstein-Barr virus. Histopathology 1994;25:88-90.

25 Lu D, Estalilla OC, Manning JT, et al. Sinus histiocytosis with massive lymphadenopathy and malignant lymphoma involving the same lymph node: a report of four cases and review of the literature. Mod Pathol 2000;13:414-9.

26 Falk S, Stutte HJ, Frizzera G. Hodgkin's disease and sinus histiocytosis with massive lymphadenopathy-like changes. Histopathology 1991;19:221-4.

27 Moore JC, Zhao X, Nelson EL. Concomitant sinus histiocytosis with massive lymphadenopathy (Rosai-Dorfman disease) and diffuse large B-cell lymphoma: a case report. J Med Case Rep 2008;2:70. 
28 Shoda H, Oka T, Inoue M, et al. Sinus histiocytosis with massive lymphadenopathy associated with malignant lymphoma. Intern Med 2004;43:741-5.

29 Koduru PR, Susin M, Kolitz JE, et al. Morphological, ultrastructural, and genetic characterization of an unusual T-cell lymphoma in a patient with sinus histiocytosis with massive lymphadenopathy. Am J Hematol 1995;48:192-200.

30 Tiwari V, Pareek A, Ghori H, et al. Rosai Dorfman disease and peripheral T-cell lymphoma: a rare co-occurrence. J Postgrad Med 2019;65:62-3.

31 Garg KK, Singh H. Sinus histiocytosis with massive lymphadenopathy (RosaiDorfman disease) and anaplastic large cell lymphoma. Eur J Case Rep Intern Med 2017;4:000605.

32 Shelley AJ, Kanigsberg N. A unique combination of Rosai-Dorfman disease and mycosis fungoides: a case report. SAGE Open Med Case Rep 2018;6:2050313X1877219.

33 Rangwala AF, Zinterhofer LJ, Nyi KM, et al. Sinus histiocytosis with massive lymphadenopathy and malignant lymphoma. An unreported association. Cancer 1990;65:999-1002.

34 Foucar E, Rosai J, Dorfman R. Sinus histiocytosis with massive lymphadenopathy (Rosai-Dorfman disease): review of the entity. Semin Diagn Pathol 1990;7:19-73.

35 Garces S, Yin CC, Patel KP, et al. Focal Rosai-Dorfman disease coexisting with lymphoma in the same anatomic site: a localized histiocytic proliferation associated with MAPK/ERK pathway activation. Mod Pathol 2019;32:16-26.

36 Maia DM, Dorfman RF. Focal changes of sinus histiocytosis with massive lymphadenopathy (Rosai-Dorfman disease) associated with nodular lymphocyte predominant Hodgkin's disease. Hum Pathol 1995;26:1378-82.

37 Lossos IS, Okon E, Bogomolski-Yahalom V, et al. Sinus histiocytosis with massive lymphadenopathy (Rosai-Dorfman disease): report of a patient with isolated renotesticular involvement after cure of non-Hodgkin's lymphoma. Ann Hematol 1997;74:41-4.

38 Edelman A, Patterson B, Donovan K, et al. Rosai-Dorfman disease with a concurrent mantle cell lymphoma. JAAD Case Rep 2019;5:40-3.

39 Gorodetskiy VR, Klapper W, Probatova NA, et al. Simultaneous occurrence of RosaiDorfman disease and nodal marginal zone lymphoma in a patient with Sjögren's syndrome. Case Rep Hematol 2018;2018:7930823.

40 Pang CS, Grier DD, Beaty MW. Concomitant occurrence of sinus histiocytosis with massive lymphadenopathy and nodal marginal zone lymphoma. Arch Pathol Lab Med 2011;135:390-3.

41 Krzemieniecki K, Pawlicki M, Margañska K, et al. The Rosai-Dorfman syndrome in a 17-year-old woman with transformation into high-grade lymphoma. A rare disease presentation. Ann Oncol 1996;7:977

42 Melikyan AL, Kovrigina AM, Gilyazitdinova EA, et al. [A case of sinus histiocytosis with massive lymphadenopathy (Rosai-Dorfman disease) in a patient with diffuse large B-cell lymphoma and chronic hepatitis B virus infection]. Ter Arkh 2012;84:66-70.

43 Zanelli M, Goteri G, Mengoli MC, et al. Rosai-Dorfman disease involving bone marrow in association with acute myeloid leukemia. Int J Surg Pathol 2019;27:396-8.

44 Castro ECC, Blazquez C, Boyd J, et al. Clinicopathologic features of histiocytic lesions following all, with a review of the literature. Pediatr Dev Pathol 2010;13:225-37.

45 Allen MR, Ninfo V, Viglio A, et al. Sinus histiocytosis with massive lymphadenopathy (Rosai-Dorfman disease) in a Girl previously affected by acute lymphoblastic leukemia. Med Pediatr Oncol 2001;37:150-2.

46 Llamas-Velasco M, Cannata J, Dominguez I, et al. Coexistence of Langerhans cell histiocytosis, Rosai-Dorfman disease and splenic lymphoma with fatal outcome after rapid development of histiocytic sarcoma of the liver. J Cutan Pathol 2012;39:1125-30

47 Venkataraman G, McClain KL, Pittaluga S, et al. Development of disseminated histiocytic sarcoma in a patient with autoimmune lymphoproliferative syndrome and associated Rosai-Dorfman disease. Am J Surg Pathol 2010;34:589-94.

48 Cohen-Barak E, Rozenman D, Schafer J, et al. An unusual co-occurrence of Langerhans cell histiocytosis and Rosai-Dorfman disease: report of a case and review of the literature. Int J Dermatol 2014;53:558-63.

49 O'Malley DP, Duong A, Barry TS, et al. Co-occurrence of Langerhans cell histiocytosis and Rosai-Dorfman disease: possible relationship of two histiocytic disorders in rare cases. Mod Pathol 2010;23:1616-23.

50 Wang K-H, Cheng C-J, Hu C-H, et al. Coexistence of localized Langerhans cell histiocytosis and cutaneous Rosai-Dorfman disease. Br J Dermatol 2002;147:770-4.

51 Sachdev R, Shyama J. Co-existent Langerhans cell histiocytosis and Rosai-Dorfman disease: a diagnostic rarity. Cytopathology 2008;19:55-8.

52 Razanamahery J, Diamond EL, Cohen-Aubart F, et al. Erdheim-Chester disease with concomitant Rosai-Dorfman like lesions: a distinct entity mainly driven by MAP2K1. Haematologica 2020;105:e5-8.

53 Vaiselbuh SR, Bryceson YT, Allen CE, et al. Updates on histiocytic disorders. Pediatr Blood Cancer 2014;61:1329-35.

54 Moynihan LM, Bundey SE, Heath D, et al. Autozygosity mapping, to chromosome $11 \mathrm{q} 25$, of a rare autosomal recessive syndrome causing histiocytosis, joint contractures, and sensorineural deafness. Am J Hum Genet 1998;62:1123-8.

55 Kismet E, Köseoglu V, Atay AA, et al. Sinus histiocytosis with massive lymphadenopathy in three brothers. Pediatr Int 2005;47:473-6.
56 Rossbach H-C, Dalence C, Wynn T, et al. Faisalabad histiocytosis mimics RosaiDorfman disease: brothers with lymphadenopathy, intrauterine fractures, short stature, and sensorineural deafness. Pediatr Blood Cancer 2006;47:629-32.

57 Molho-Pessach V, Agha Z, Aamar S, et al. The H syndrome: a genodermatosis characterized by indurated, hyperpigmented, and hypertrichotic skin with systemic manifestations. J Am Acad Dermatol 2008;59:79-85.

58 Doviner V, Maly A, Ne'eman Z, et al. H syndrome: recently defined genodermatosis with distinct histologic features. A morphological, histochemical, immunohistochemical, and ultrastructural study of 10 cases. Am J Dermatopathol 2010;32:118-28.

59 Avitan-Hersh $\mathrm{E}$, Mandel $\mathrm{H}$, Indelman $\mathrm{M}$, et al. A case of $\mathrm{H}$ syndrome showing immunophenotye similarities to Rosai-Dorfman disease. Am J Dermatopathol 2011:33:47-51.

60 Melki I, Lambot K, Jonard L, et al. Mutation in the SLC29A3 gene: a new cause of a monogenic, autoinflammatory condition. Pediatrics 2013;131:e1308-13.

61 Tschen J, Martinelli P, Cohen P. Acquired progressive lymphangioma. Dermatología Cosmética Médica y Quirúrgica 2009;7:49-53.

62 Molho-Pessach V, Ramot Y, Camille F, et al. H syndrome: the first 79 patients. J Am Acad Dermatol 2014;70:80-8.

63 Bolze A, Abhyankar A, Grant AV, et al. A mild form of SLC29A3 disorder: a frameshift deletion leads to the paradoxical translation of an otherwise noncoding mRNA splice variant. PLoS One 2012:7:e29708-11.

64 Maric I, Pittaluga S, Dale JK, et al. Histologic features of sinus histiocytosis with massive lymphadenopathy in patients with autoimmune lymphoproliferative syndrome. Am J Surg Pathol 2005;29:903-11.

65 Brenn T, Calonje E, Granter SR, et al. Cutaneous Rosai-Dorfman disease is a distinct clinical entity. Am J Dermatopathol 2002;24:385-91.

66 Destombes P, Destombes M, Martin L. Pseudotumoral lymph node lipidic histiocytosis. Further case in a young Martinique woman. Bull Soc Pathol Exot 1972;65:481-8.

67 Andriko JA, Morrison A, Colegial CH, et al. Rosai-Dorfman disease isolated to the central nervous system: a report of 11 cases. Mod Pathol 2001;14:172-8.

68 Kong Y-Y, Kong J-C, Shi D-R, et al. Cutaneous Rosai-Dorfman disease: a clinical and histopathologic study of 25 cases in China. Am J Surg Pathol 2007;31:341-50.

69 Abla O, Jacobsen E, Picarsic J, et al. Consensus recommendations for the diagnosis and clinical management of Rosai-Dorfman-Destombes disease. Blood 2018;131:2877-90.

70 Al-Khateeb THH. Cutaneous Rosai-Dorfman disease of the face: a comprehensive literature review and case report. J Oral Maxillofac Surg 2016;74:528-40.

71 Patel MH, Jambhekar KR, Pandey T, et al. A rare case of extra nodal Rosai-Dorfman disease with isolated multifocal osseous manifestation. Indian J Radiol Imaging 2015;25:284-7.

72 Sandoval-Sus JD, Sandoval-Leon AC, Chapman JR, et al. Rosai-Dorfman disease of the central nervous system: report of 6 cases and review of the literature. Med 2014:93:165-75.

73 Boissaud-Cooke MA, Bhatt K, Hilton DA, et al. Isolated intracranial Rosai-Dorfman disease: case report and review of the literature. World Neurosurg 2020;137:239-42.

74 Taufiq M, Khair A, Begum F, et al. Isolated intracranial Rosai-Dorfman disease. Case Rep Neurol Med 2016:2016:1-4.

75 Demicco EG, Rosenberg AE, Björnsson J, et al. Primary Rosai-Dorfman disease of bone: a clinicopathologic study of 15 cases. Am J Surg Pathol 2010;34:1324-33.

76 Zhang Y, Chen $\mathrm{H}$. Image gallery: generalized cutaneous Rosai-Dorfman disease presenting as Acneiform lesions. Br J Dermatol 2019;180:e36.

77 El-Kamel M, Selim M, Gawad M. A new presentation of isolated cutaneous RosaiDorfman disease: eruptive xanthoma-like lesions. Indian J Dermatol Venereol Leprol 2018;17.

78 Rajyalakshmi R, Akhtar M, Swathi Y, et al. Cytological diagnosis of Rosai-Dorfman disease: a study of twelve cases with emphasis on diagnostic challenges. J Cytol 2020;37:46-52.

79 Kuo T-tong, Chen T-C, Lee L-Y, et al. IgG4-positive plasma cells in cutaneous Rosai-Dorfman disease: an additional immunohistochemical feature and possible relationship to IgG4-related sclerosing disease. J Cutan Pathol 2009;36:1069-73.

80 Menon MP, Evbuomwan MO, Rosai J, et al. A subset of Rosai-Dorfman disease cases show increased IgG4-positive plasma cells: another red herring or a true association with IgG4-related disease? Histopathology 2014;64:455-9.

81 Zhang $X$, Hyjek E, Vardiman J. A subset of Rosai-Dorfman disease exhibits features of IgG4-related disease. Am J Clin Pathol 2013;139:622-32.

82 Shrestha B, Sekiguchi H, Colby TV, et al. Distinctive pulmonary histopathology with increased IgG4-positive plasma cells in patients with autoimmune pancreatitis: report of 6 and 12 cases with similar histopathology. Am J Surg Pathol 2009;33:1450-62.

83 El-Kersh K, Perez RL, Guardiola J. Pulmonary lgG4+ Rosai-Dorfman disease. BMJ Case Rep 2013;2013. doi:10.1136/bcr-2012-008324. [Epub ahead of print: $10 \mathrm{Apr} 2013$ ].

84 Roberts SS, Attanoos RL. IgG4+ Rosai-Dorfman disease of the lung. Histopathology 2010;56:662-4.

85 Deshpande V, Zen Y, Chan JK, et al. Consensus statement on the pathology of IgG4related disease. Mod Pathol 2012;25:1181-92.

86 Liu L, Perry AM, Cao W, et al. Relationship between Rosai-Dorfman disease and IgG4related disease: study of 32 cases. Am J Clin Pathol 2013;140:395-402. 
87 Richter JT, Strange RG, Fisher SI, et al. Extranodal Rosai-Dorfman disease presenting as a cardiac mass in an adult: report of a unique case and lack of relationship to IgG4-related sclerosing lesions. Hum Pathol 2010;41:297-301.

88 Chen T-D, Lee L-yu. Rosai-Dorfman disease presenting in the parotid gland with features of IgG4-related sclerosing disease. Arch Otolaryngol Head Neck Surg 2011;137:705-8.
89 Khosroshahi A, Wallace ZS, Crowe JL, et al. International consensus guidance statement on the management and treatment of IgG4-related disease. Arthritis Rheumatol 2015;67:1688-99.

90 Pulsoni A, Anghel G, Falcucci P, et al. Treatment of sinus histiocytosis with massive lymphadenopathy (Rosai-Dorfman disease): report of a case and literature review. Am J Hematol 2002;69:67-71. 